\title{
Septic arthritis of the knee: Presentation of a novel irrigation-suction system tested in a cadaver study
}

\author{
Atesch Ateschrang ${ }^{1}$, Dirk Albrecht ${ }^{1 *}$, Steffen Schröter ${ }^{1}$, Bernhard Hirt ${ }^{2}$, Kuno Weise $^{1}$ and Jürgen H Dolderer ${ }^{3}$
}

\begin{abstract}
Background: The established treatment for bacterial arthritis of the knee joint is arthroscopic surgery with irrigation and debridement. The aim of this article is to summarize the relevant data in treating bacterial arthritis of the knee joint, and based on these findings to present a novel irrigation suction system, tested in a cadaver study, as an additional tool in the postoperative treatment phase of arthroscopic surgery for knee joint infections.

Method: The novel automated irrigation-suction system presented here was compared to conventional continuous suction irrigation in a total of six knee joints. All knee joints were filled with $80 \mathrm{ml}$ methylene blue stain and rinsed by two different methods. Fluid specimens were taken after ten and twenty minutes to be compared by photometric extinction measurement at a wave length of $500 \mathrm{~nm}$.

Results: After ten minutes, the average extinction was $e_{1 C}=0.8$ for the continuous suction irrigation and $e_{1 \mathrm{~N}}=0.4$ for the novel irrigation-suction system. After twenty minutes, we recorded an average extinction of $e_{2 C}=0.3$ for continuous suction irrigation and $e_{2 \mathrm{~N}}=0.001$ for the novel irrigation-suction system. The students $t$-test revealed superior results after ten and twenty minutes of washing out the knee joints with a $p<0.001$ for the novel irrigation-suction system.
\end{abstract}

Conclusion: A novel irrigation-suction system may be an effective tool for postoperative knee joint irrigation in arthroscopic therapy for bacterial arthritis of the knee. Further animal studies are needed to verify the effects in vivo.

\section{Background}

Septic arthritis is a serious problem, with the knee the most frequently involved joint in adults [1-3]. Clinical outcome not only depends on the number and type of the agent involved and the general state of the patient, but also on the speed and decisiveness with which the diagnosis is made. Previous studies made clear that immediate treatment is essential to avoid unsatisfactory results $[1,4-7]$. While the established treatment has changed over the last few decades, the old principle 'ubi pus, ibi evacua' has maintained its relevance. Accepted therapy includes joint decompression with mechanical irrigation reducing the amount of infecting organisms, fibrin coatings and necrotic cell detritus combined with the use of antibiotics to produce full functional recovery [3-7]. Primary open arthrotomy with early subtotal

\footnotetext{
* Correspondence: dalbrecht@bgu-tuebingen.de

'Department of Traumatology and Reconstructive Surgery, BG-Trauma and Medical Centre Tübingen, Eberhard Karls University Tübingen,

Schnarrenbergstr. 95, 72076 Tübingen, Germany

Full list of author information is available at the end of the article
}

synovectomy and immobilisation of the knee [7-9] has been replaced by arthroscopic surgery and early passive motion in treating bacterial arthritis [3-6].

The aim of this article is to summarise the accepted therapy of bacterial knee joint infections, and to present a novel irrigation-suction system that was tested in a cadaver study to be used in the postoperative treatment phase of arthroscopic joint surgery. To our knowledge there is as yet no publication on this topic with the stated aim of developing a novel automatic irrigation-suction system as an additional tool for the postoperative aftercare of septic arthritis of the knee based on pathophysiological findings. Despite of a careful search of all internationally available arthroscopic pumps and devices, we were not able to locate any such device on the market.

\section{Accepted therapy}

Clinical and experimental studies have shown a clear relationship between early and aggressive initiation of surgical treatment and success of therapy in septic arthritis of the knee [3-6,10-17]. If an infected knee

\section{Ciomed Central}


joint is diagnosed early, and appropriate antibiotic therapy is initiated immediately, arthrotomy and needle aspiration can effectively eradicate the infection with only minimum damage to the cartilage [18]. Despite the positive results reported for repeated needle aspiration or tidal irrigation [18-20], sufficient drainage of the knee joint by these methods may be suboptimal $[5,6,21]$. Before the introduction of arthroscopy for the treatment of septic arthritis, open surgery with an early synovectomy was recommended [9,22-24]. The recommendations for postoperative aftercare, such as immobilization of the knee joint for 1 to 3 weeks versus immediate continuous passive motion (CPM) have already been discussed in the literature [9,23-27]. Salter et al. demonstrated that joint immobilization might lead to cartilage dystrophy via permanent localized pressure [26], with CPM therapy later being recommended $[6,25,28,29]$. Another controversial tool for postoperative aftercare, especially after open arthrotomy, was continuous suction irrigation therapy, which was based on the findings of Willenegger [30]. The aim was to wash out the joint and gain a dilution of aggressive proteolytic enzymes and reduction of the organisms. Turcic et al. demonstrated less effectiveness of conventional drain placement using a mathematical stream model compared to increased distance of the drains and the use of $t$-drains [31]. The main disadvantage of the continuous suction irrigation is the development of the so-called highway effect $[5,10,14]$. By taking the path of least resistance, the irrigation fluid flows through the joint without necessarily reaching all joint compartments. Jackson [11] and Jackson and Parsons [32] proposed a distension-irrigation technique in which the surgeon first irrigates and debrides the joint, then inserts two drains into the joint, distending the joint through the drains with saline solution, including antibiotic and mucolytic agents added over 3 hours, finally draining the joint for one more hour. In addition to the local distension-irrigation process, intravenous antibiotics are also administered. Some authors have recommended $[33,34]$ or rejected $[35,36]$ the use of continuous suction irrigation drains with antibiotics added to the irrigation solution. However, conclusive data have shown that antibiotic concentration in joint fluid can be achieved in adequate amounts after systemic use, leading the majority of authors not to add antibiotics into the irrigation solution [4,6,37-40].

In the 1980s arthroscopic management for septic knee arthritis was introduced. The authors achieved good results with arthroscopic treatment, and some authors used stages of joint infection based on pathophysiological findings (see table 1 for staging of Gächter and Jensen) or clinical appearance (see table 1 for staging of Kuner) with the purpose of recommending stage-dependent surgical therapy $[5,6,10,11,14,25,28,29,33,35,37,41-43]$. According to the literature the staging, as described by Gächter, was the most frequently used $[4,6,37,42,44]$. Studies could show that for stages Gächter I-III arthroscopic joint decompression with irrigation and debridement is effective. This may be repeated, if the septic process persists with further systemic antibiotic therapy $[6,28,37]$. This rate of repeated arthroscopic joint surgery was $0-41 \%$ and depended on the initial stage of the infection and time lapse between surgery and the onset of first infection signs $[4,6,28,29,35,37,45,46]$. Open surgery with arthrotomy is needed for stage Gächter IV or in cases of persisting infections after repeated arthroscopic joint surgery [6,37]. This occurred in $0-10 \%$ of the cases $[4,6,28,29,35,37,45]$. Late recurrences of joint infection after an asymptomatic interval are rare but can occur in $10 \%$ of the cases $[4,6,28,29,35,37,45]$. The overall healing rate of arthroscopic therapy in treating knee joint infections was high to a value of $90-100 \%[4,6,28,29,35,37,45,47-49]$.

The surgical treatment protocol for arthroscopic therapy of septic arthritis is joint decompression, elimination of the causative organisms by intensive lavage of the joint (with a minimum of 10 litres) with simultaneous elimination of proteolytic and lysosomal enzymes as well as toxins $[1,4-7,10,11,28,35,37,41,45,47-50]$. Debridement of necrotic soft tissues with the aim of preserving the synovial membrane as an immune competent structure and natural barrier, is recommended by the majority of the authors [4-6,10,25,28,29,33,35,37,44,47-49]. There is general consent for the use of culture-specific antibiotic therapy for about four to eight weeks. The protective effect of CPM should be used in postoperative aftercare [4,25-28,49].

Interestingly, some authors have recommended the use of continuous irrigation-suction drains after arthroscopic joint lavage $[4,25,29,33]$, while others have recommended the so-called distension-irrigation described by Jackson $[11,32,49]$. Riel et al. could demonstrate a positive effect of this type of irrigation during the aftercare of arthroscopic treatment and concluded that further arthroscopic joint lavage could be reduced while conceding that their sample size was small and that further trials are needed [49]. The main weakness of the data concerning the aftercare with different irrigation modalities is the fact that the treated patient groups were very heterogeneous in terms of infection, etiology, infection staging, and postoperative irrigation modalities $[4,6,11,25,29,32,33,49]$.

\section{Methods \\ Novel pressure- and flow-controlled irrigation-suction system}

The first step of the accepted therapy in septic arthritis is arthroscopic surgery with joint decompression, debridement, and joint irrigation following the detailed recommendations as described above. To optimize atraumatic joint decontamination, we suggest an efficient intra-articular 
Table 1 Stages of joint infection [5]

\begin{tabular}{ll}
\hline Gächter & The classification according to Gächter included IV Stages: \\
\hline Stage I & Opacity of fluid, redness of the synovial membrane, possible petechial bleeding, no radiological alterations. \\
\hline Stage II & Severe inflammation, fibrinous deposition, pus, no radiologic alterations. \\
\hline Stage III & $\begin{array}{l}\text { Thickening of the synovial membrane, compartment formation ("sponge-like" arthroscopic view, especially in the suprapatellar pouch), no } \\
\text { radiologic alterations. }\end{array}$ \\
\hline Stage IV & $\begin{array}{l}\text { Aggressive pannus with infiltration of the cartilage, possibly undermining the cartilage, radiological signs of subchondral osteolysis, } \\
\text { possible osseous erosions and cysts. }\end{array}$ \\
\hline Jensen & The classification according to Jensen included III stages: \\
\hline Stage I & Opaque effusion with high cell count, hyperaemia of the synovium. \\
\hline Stage II & Putrid effusion, fibrin coatings, synovial hypertrophy with petechial bleeding. \\
\hline Stage III & Severe villous synovitis with (partial) tamponade of the joint, synovial necrosis, synovial adhesions, cartilage destruction. \\
\hline Kuner & The classification according to Kuner was more a clinical description rather than an arthroscopic staging: \\
\hline Stage I & Purulent synovitis \\
\hline Stage II & Joint empyema \\
\hline Stage III & Panarthritis \\
\hline Stage IV & Chronic arthritis. \\
\hline
\end{tabular}

irrigation-suction for the postoperative treatment phase using drains, which have been positioned during arthroscopy.

The primary aim of our investigation was to develop a fully automatic device, which is much more efficient (defined by volume of irrigation per time) than the technique described by Jackson and Parsons [32], while applying, though, their principle. To achieve this, we needed an irrigation and suction pump. For the irrigating pump, we used a conventional arthroscopy pump from Arthrex ${ }^{\circledR}$ providing pressure and flow-controlled conditions. For the suction pump, we used one from Medap ${ }^{\circledR}$ with varying adjustable pressures (negative barometric pressures up to 600 mbar). The function of both pumps needed to be coordinated by a third device to achieve fully automatic irrigation and suction of the joint, while at the same time avoiding simultaneous suction and irrigation. We solved this requirement by developing a novel prototype, which independently clamps the in- and outflow drains. This prototype was developed in cooperation with a working group at a Technical University (Figure 1 and 2). To achieve maximum time flexibility of the irrigation and suction modalities, we defined and described the following four working steps with different time intervals, which can be chosen individually by the treating surgeon and supervised by the nursing staff and the patient:

T1 (time for irrigation in seconds): The joint is filled up and irrigated by the arthroscopic pump through the inflow drain and with defined pressure (e.g. between 20 and $80 \mathrm{mmHg}$ ) and flow (adjustable pumping volume per time). The arthroscopic pump keeps the joint distended (maintaining the chosen pressure) for the defined time period (T1) chosen by the surgeon. During this period the outflow drain is clamped in order that the suction pump remains idle.

D1 (Delay between irrigation and suction in seconds): Inflow and outflow drains are clamped simultaneously, while the joint is still distended. This time interval can be chosen by the surgeon.

T2 (Time for suction in seconds): The arthroscopic pump is idle by clamping the inflow drain. Suction is provided at this point by the de-clamped outflow drain. This time for suction can be adjusted by the surgeon individually.

D2 (Delay between suction and the onset of irrigation, end of one working circle): Now, both drains are clamped for a time period chosen by the surgeon, before the inflow drain is being de-clamped and another working cycle may begin.

The advantage of this automatic working system is that the surgeon is able to regulate the flow (volume per time) and the pressure for irrigation and suction. Painful joint distension can be reduced for short time periods or may be avoided by reducing the joint pressure due to the individual needs of the patient and pain situation. This problem was described by Jackson and Parsons [32]. Joint adhesions can be avoided by distending the capsule, providing simultaneously a very efficient postoperative joint decontamination, which is an important aspect of the pathophysiology and can be carried out using this additional tool for the postoperative aftercare of arthroscopy $[4,29,32,49]$.

The prototype was equipped with an emergency stop button for the patient in case of a leakage into the soft tissue envelope with the danger of a compartment syndrome, if swelling or pain develops (Figure 1 and 2). 


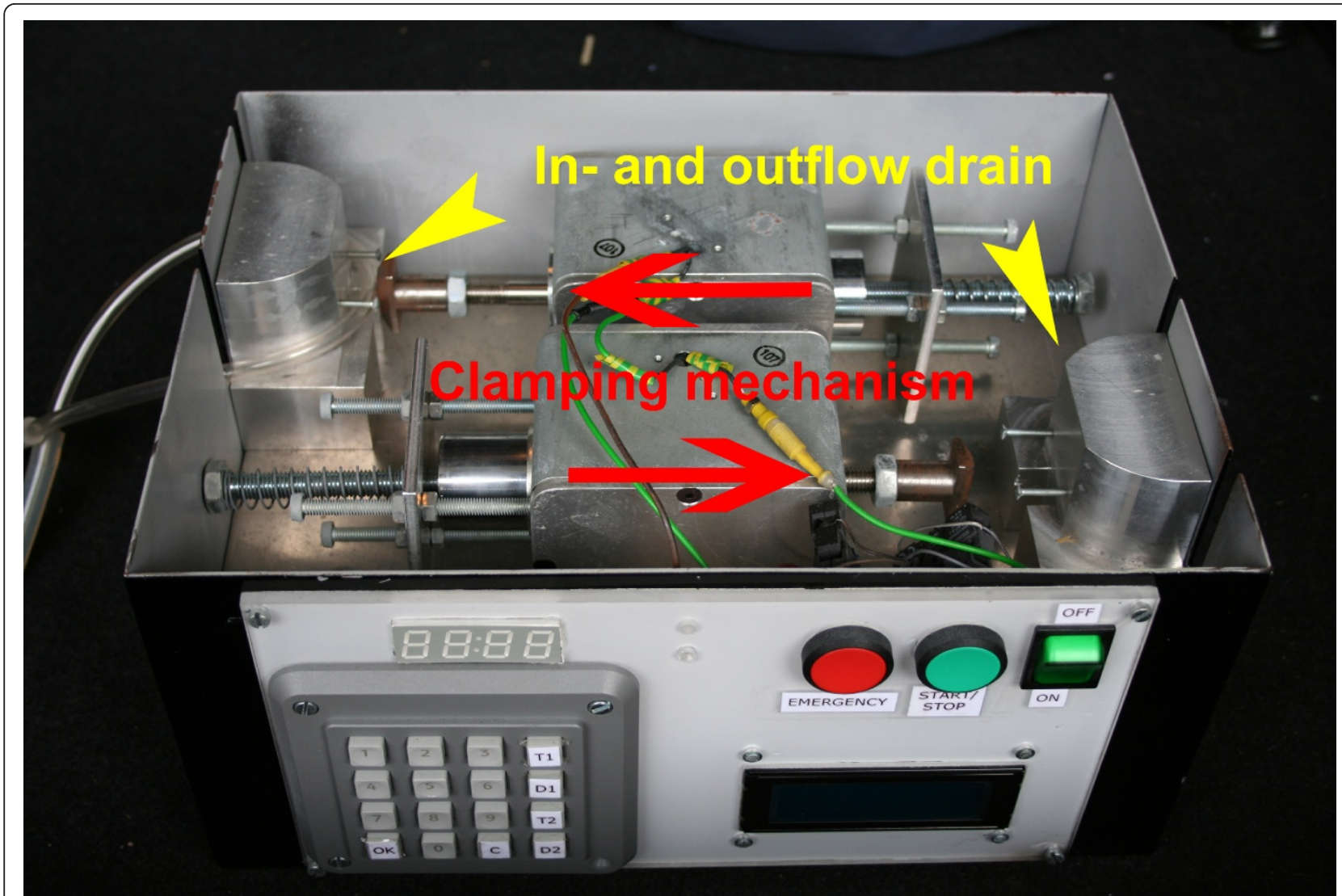

Figure 1 Prototype coordinating the function of the arthroscopy, and suction pump.

We tested the effectiveness of treatment in a cadaveric study by comparing normal continuous suction irrigation versus the novel irrigation-suction system using our prototype in three cadavers. The knee joints were filled up with a volume of $80 \mathrm{ml}$ methylene blue stain in formalin-fixed knee joints after three drains were placed arthroscopically. Two drains were placed antero-medially and laterally. The third drain was placed in the suprapatellar recessus for both irrigation systems (Figure 3 and 4). For both irrigation systems, the superior drain was used as the inflow tube and both anterior drains were used as outflow tubes. Simulation of postoperative irrigation thus began using physiologic saline solution.

The continuous suction irrigation system was characterized with the following parameters: The inflow tube was connected with conventional infusion systems using hydrostatic pressure (in a height of $1.8 \mathrm{~m}$ ), while the outflow tubes were connected with the suction pump $\left(\right.$ Medap $\left.^{(\mathbb{R}}\right)$, providing a continuous flow through the joint with a suction pressure of 300 mbar.

The novel irrigation system was characterized with the following parameters: The filling pressure was 40 $\mathrm{mmHg}$ (and high flow) with a suction pressure chosen at $300 \mathrm{mbar}(\mathrm{T} 1=10 \mathrm{sec}, \mathrm{D} 1=4 \mathrm{sec}, \mathrm{T} 2=10 \mathrm{sec}, \mathrm{D} 2$
$=4 \mathrm{sec}$ ). To compare effectiveness we took a fluid specimen after 10 and 20 minutes and checked extinction via photometry at a wavelength of $500 \mathrm{~nm}$. A line measure had previously been obtained by diluting the methylene blue stain in defined fractions. The extinction analysis was blinded.

This trial conforms to the Helsinki Declaration and to local legislation. The ethics committee of the EberhardKarls-University of Tübingen approved this trial.

\section{Results}

The extinction measurements showed more effectiveness after 10 and 20 minutes for the novel irrigationsuction system. After ten minutes the average extinction was $\mathrm{e}_{1 \mathrm{C}}=0.8$ for the continuous suction irrigation and $\mathrm{e}_{1 \mathrm{~N}}=0.4$ for the novel irrigation-suction system. After twenty minutes, we recorded an average extinction of $\mathrm{e}_{2 \mathrm{C}}=0.3$ for continuous suction irrigation and $\mathrm{e}_{2 \mathrm{~N}}=$ 0.001 (macroscopic clear irrigation fluid) for the novel irrigation-suction system. As the irrigating solution was clear after twenty minutes, we stopped irrigation and performed an arthrotomy of all six knee joints. In the knee joints with continuous suction irrigation, methylene blue stain solution was visible in the postero-medial 


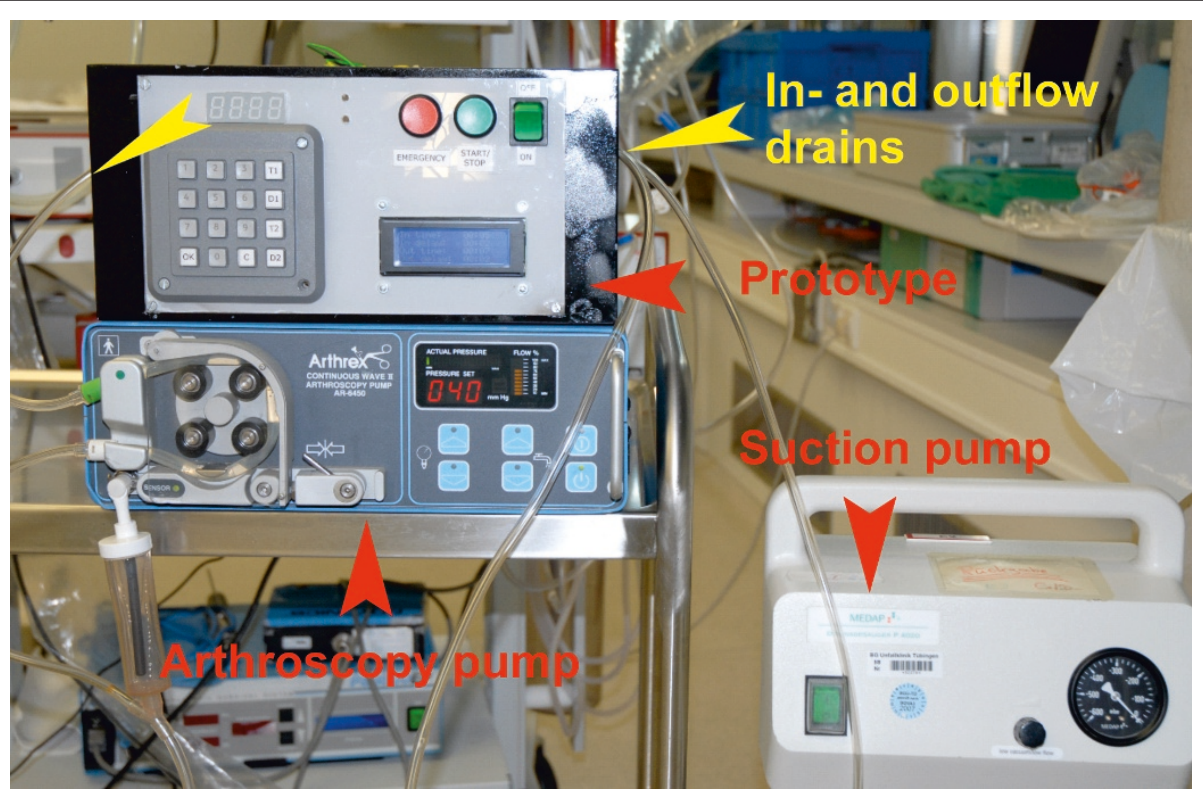

Figure 2 Prototype, arthroscopy, and suction pump

and lateral pouch and the posterior part of the notch, while clear solution was found in the knee joints irrigated by the novel irrigation-suction system. The students t-test showed significant differences, with a positive value for a confidence interval of $95 \%$ and a $\mathrm{p}<$

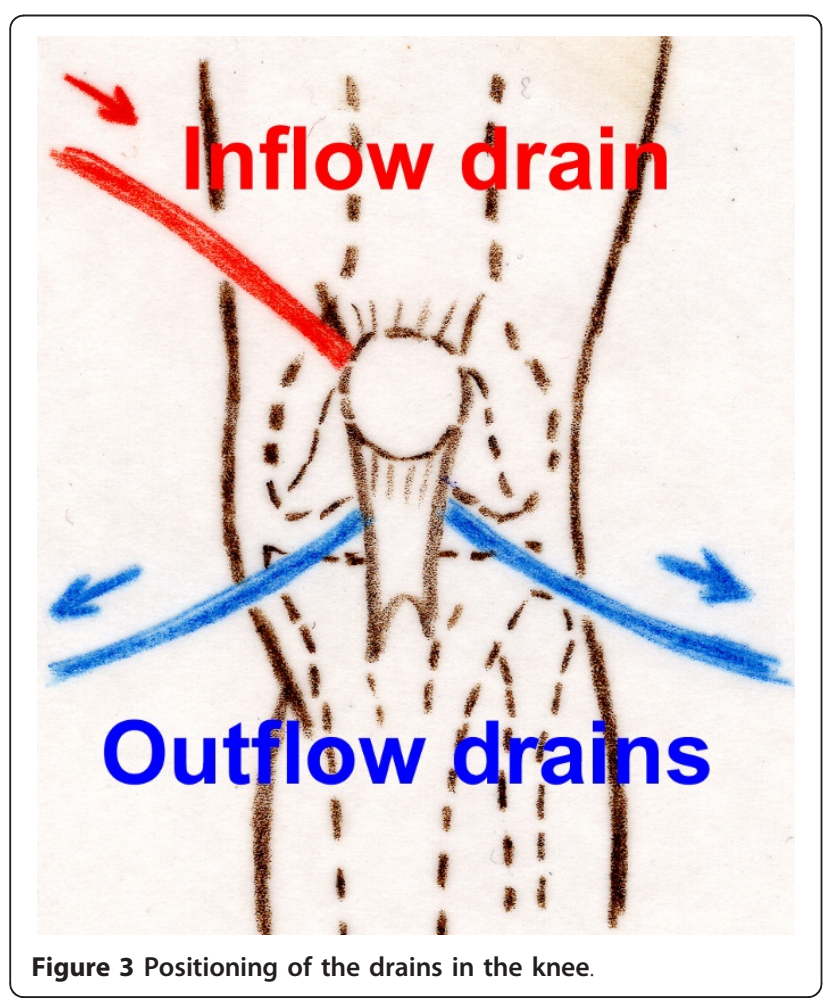

0.001, demonstrating a superior clearance for the novel irrigation-suction.

\section{Discussion}

Bacterial arthritis of the knee joint can be treated effectively by arthroscopy with positive results. Very important aspects of the pathophysiology and the consecutive therapy of joint infection are early joint decompression with joint irrigation and arthroscopic debridement.

Studies could show that for stages Gächter I-III arthroscopic joint decompression, irrigation and debridement is effective and can be repeated, if the infection persists $[6,28,37]$. The rate of repeated arthroscopy amounted to $0-41 \%$ and depended on the initial stage of the infection and time lapse between surgery and the onset of first infection signs $[4,6,28,29,35,37,45,46]$. Open surgery with arthrotomy is needed for stage Gächter IV joint infections or in cases of persisting infections after repeated arthroscopic joint surgery [6,37]. Late recurrences of joint infections after an asymptomatic interval are rare but can amount up to $10 \%[4,6,28,29,35,37,45]$. The overall success and healing rate of arthroscopic therapy in treating knee joint infections was high (90-100\%) [4,6,28,29,35,37,45,47-49].

Some authors rejected and others recommended the use of continuous irrigation-suction drains after arthroscopic joint irrigation $[4,6,25,29,33]$, while others recommended the so-called distension-irrigation described by Jackson $[18,32,49]$. Riel et al. could demonstrate a positive effect in using this type of irrigation during the aftercare of arthroscopic surgery and concluded that further arthroscopic joint irrigation and the arthroscopic 


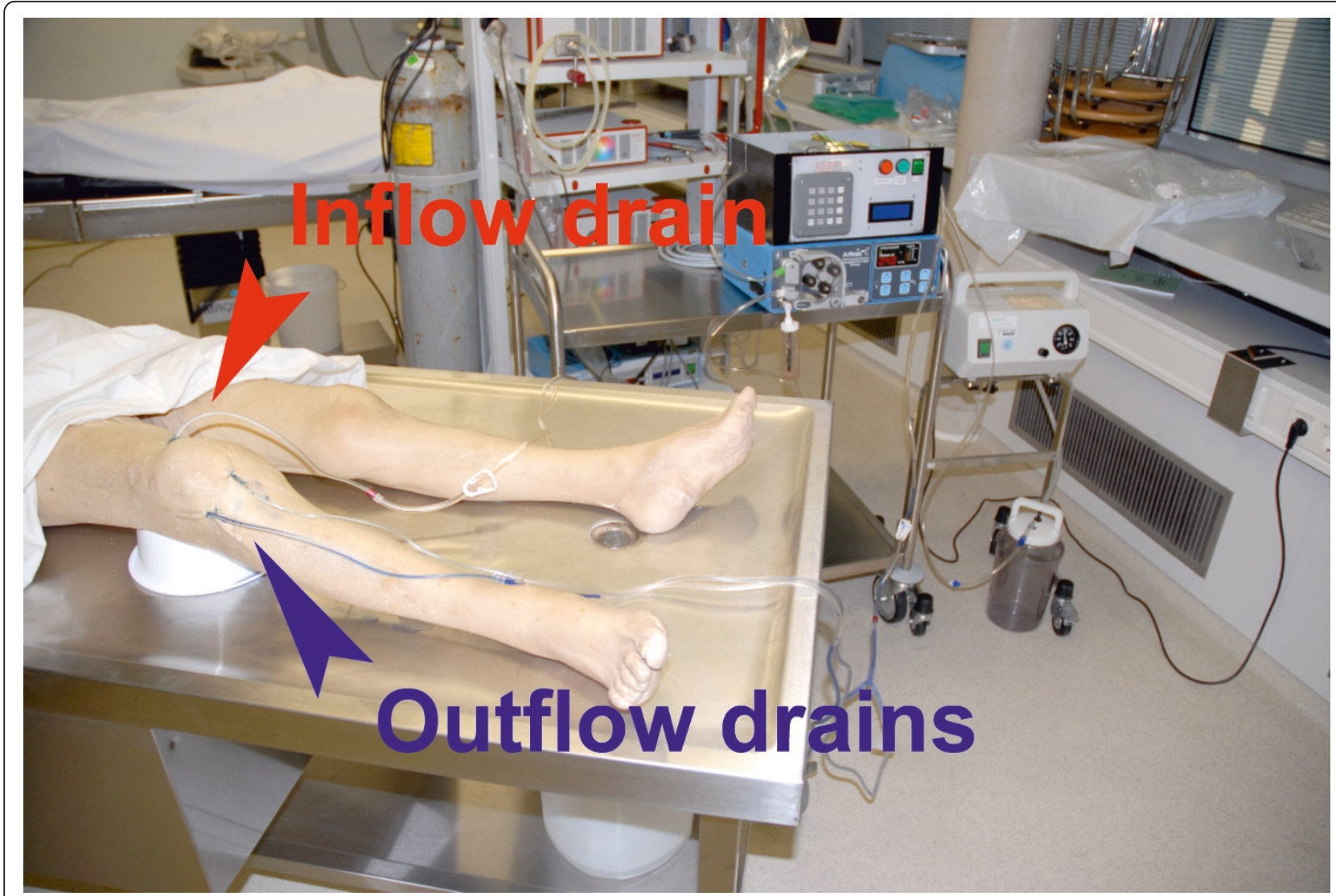

Figure 4 Setting in the anatomic institute

operating time could be reduced, while taking into account that their sample size was small and that further trials were needed [49]. The novel irrigation-suction system presented here provides an effective automatic joint irrigation regarding the irrigated fluid volume per time. This system has similar characteristics as the distensionirrigation described by Jackson and Parsons concerning the working cycle [32]. However, it has the great advantage of imitating arthroscopic irrigation characteristics. Regarding the components and the working cycle of this novel irrigation system, one will realize, that properties of the arthroscopic irrigation are provided and commenced during the postoperative aftercare. There are three main hypothesized advantages to continue an arthroscopic like irrigation in the postoperative phase: reducing the rate of repeated arthroscopic surgery and time for surgical irrigation, reducing joint adhesions with potential quicker recovery and better range of motion. We could not identify similar studies testing effectiveness of irrigating knee joints by different techniques, so that a further comparison and discussion of these results was limited. The mentioned hypothetic advantages of this novel irrigation system must be proven by further trials.

\section{Conclusions}

This novel irrigation-suction system is more effective than conventional continuous suction irrigation and simultaneously avoiding highway effects by distending the joint capsule.

However, this system should be tested in cooperation with an industrial partner using different joints and further anatomic regions. The next steps would be to perform appropriate animal studies, the development and certification, and clinical tests such as a prospective randomized trial.

There seems to be a huge potential for the application of this novel device. Applications may include joint infections but also the postoperative care of other septic diseases such as bacterial peritonitis [50].

The value of an automated irrigation and suction device in the postoperative care is a new and promising technique, which will be evaluated by further studies.

\section{Acknowledgements}

We would like to thank Prof. Dr. rer. nat. Dominik Schoop (Technical University Esslingen, Germany) and his working group for the cooperation and building the prototype. 


\begin{abstract}
Author details
${ }^{1}$ Department of Traumatology and Reconstructive Surgery, BG-Trauma and Medical Centre Tübingen, Eberhard Karls University Tübingen, Schnarrenbergstr. 95, 72076 Tübingen, Germany. ${ }^{2}$ Institute for Anatomy, Department for Clinical Anatomy, Eberhard Karls University, Tübingen, Elfriede-Aulhorn-Straße 8, 72076 Tübingen, Germany. 'Department of Plastic, Hand and Reconstructive Surgery, BG-Trauma and Burn Centre Tübingen, Eberhard Karls University Tübingen, Schnarrenbergstr. 95, 72076 Tübingen, Germany.
\end{abstract}

\section{Authors' contributions}

AA developed the idea of the novel irrigation system and carried out the requirements catalogue of the prototype and development with the technical university the prototype, performed the cadaver tests and drafted the manuscript. DA conceived of the cadaver test, and participated in its design and helped to draft the manuscript. SS participated in the design of the study and performed the statistical analysis. $\mathrm{BH}$ conceived and participated in the cadaver test. KW helped in drafting the manuscript and helped in filtering the relevant published data. JD gave intellectual input for the entire manuscript and drafting the manuscript. All authors read and approved the final manuscript.

\section{Competing interests}

The authors declare that they have no competing interests.

Received: 24 July 2010 Accepted: 7 August 2011

Published: 7 August 2011

\section{References}

1. Smith JW, Piercy EA: Infectious arthritis. Clin Infect Dis 1995, 20:225-231.

2. Vincent GM, Amirault JD: Septic arthritis in the elderly. Clin Orthop 1990, 251:241-245

3. Esterhai J, Gelb I: Adult septic arthritis. Orthop Clin North Am 1991, 22:503-514.

4. Vispo Sera JL, Barthel T, Schmitz H, et al: Arthroscopic treatment of septic joints: prognostic factors. Arch Orthop Trauma Surg 2002, 122:204-211.

5. Lungershausen W, Markgraf E, Dorow C, et al: Joint empyema. Chirurg 1998, 69:828-835.

6. Stutz G, Kuster MS, Kleinstück F, et al: Arthroscopic management of septic arthritis: stages of infection and results. Knee Surg Sports Traumatol Arthrosc 2000, 8:270-274.

7. Lane JG, Falahee MH, Wojtys EM, et al: Pyarthrosis of the knee. Treatment considerations. Clin Orthop 1990, 252:198-204.

8. Shulman G, Waugh TR: Acute bacterial arthritis in the adult. Orthop Rev 1988, 17:955-960.

9. Hansis M, Meeder PJ, Weller S: Treatment of knee joint empyema. Zentralb/ Chir 1984, 109:1431-1436.

10. Jerosch J, Hofstetter I, Schröder M, et al: Septic arthritis: Arthroscopic management with local antibiotic treatment. Acta Orthop Bel 1995, 61:126-134.

11. Jackson RW: The Septic Knee: Arthroscopic Treatment. Arthroscopy 1985, 1:194-197.

12. Ward JA, Cohen S, Bauer W: The diagnosis and therapy of acute suppurative arthritis. Arthr Rheum 1960, 3:522-535.

13. Orchard RA, Stamp WG: Early treatment of induced supparative arthritis in rabbit knee joints. Clin Orthop 1968, 59:287-293.

14. Jensen K-U, Klein W, Dann K: Arthroscopic treatment of septic gonitis. Arthroskopie 1989, 2:104-111.

15. Schollin-Borg M, Michaelsson K, Rahme H: Presentation, outcome, and cause of septic arthritis after anterior cruciate ligament reconstruction: a case control study. Arthroscopy 2003, 19:941-947.

16. Williams RJ, Laurencin CT, Warren RF, Speciale AC, Brause BD, O'Brien S: Septic arthritis after arthroscopic anterior cruciate ligament reconstruction. Diagnosis and management. Am J Sports Med 1997, 25:261-267.

17. Nord KD, Dore DD, Deeney VF, Armstrong AL, Cundy PJ, Cole BF, Ehrlich MG: Evaluation of treatment modalities for septic arthritis with histological grading and analysis of levels of uronic acid, neutral protease, and interleukin-1. J Bone Joint Surg Am 1995, 77:258-265.

18. Goldenberg DL, Brandt KP, Cohen AS, Cathcart ES: Treatment of septic arthritis: Comparison of needle aspiration and surgery as initial modes of joint drainage. Arthritis Rheum 1975, 18:83-90.
19. Sharp JT, Lindsky MD, Duffy J, Duncan MW: Infectious arthritis. Arch Intern Med 1979, 139:1125-1130.

20. Ike RW: Tidal irrigation in septic arthritis of the knee: a potential alternative to surgery. J Rheum 1993, 20:2104-2111.

21. Bynum DK, Nunley JA, Goldner JL, Martinez S: Pyogenic arthritis: emphasis on the need for surgical drainage of the infected joint. South Med J 1982 75:1232-1235, 1238.

22. Ballard A, Burkhalter WE, Mayfield GW, Dehne E, Brown PW: The functional treatment of pyogenic arthritis of the adult knee. J Bone Joint Surg Am 1975, 57:1119-1123.

23. Giebel G, Muhr G, Tscherne H: Synovektomy in knee joint infection. Unfallheilkunde 1984, 87:52-57.

24. Hempfling $H$, Probst J: Therapy of empyema of the knee and hip. $Z$ Unfallchir Vers med Berufskr 1988, 81:21-29.

25. Draijer F, Lorentzen T, Nissen R, Havemann D: Functional treatment of surgically treated empyema of the knee joint. Unfallchirurg 1994, 97:273-277.

26. Salter $R$, Bell RS, Frederick WK: The protective effect of continous passive motion on living articular cartilage in acute septic arthritis. An experimental investigation in the rabbit. Clin Orthop 1981, 159:223-247.

27. Salter RB, Simmonds DF, Malcom BW, Rumble EJ, MacMichael D, Clements ND: The biological effect of continous passive motion of the healing of full thickness defects in articular cartiliage. An experimental investigation in the rabbit. J Bone Joint Surg Am 1980, 62:1232-1251.

28. Wirtz DC, Marth M, Miltner O, Schneider U, Zielkens KW: Septic arthritis of the knee in adults: treatment by arthroscopy or arthrotomy? Int Orthop 2001, 25:239-241.

29. Thiery JA: Arthroscopic drainage in septic arthritis of the knee: a multicenter study. Arthroscopy 1989, 5:65-69.

30. Willenegger $\mathrm{H}$ : Clinical aspects and therapy of pyogenic bone infections. Chirurg 1970, 41:215-221.

31. Turcić J, Gjetvaj G, Androcec V, Hancević J, Alfirević I, Cavcić J, Smud D: Mathematical model of hydrodynamic flow in irrigation-suction drainage. Unfallchirurg 1996, 99:435-439.

32. Jackson RW, Parsons CJ: Distension-irrigation treatment of major joint sepsis. Clin Orthop Rel Res 1973, 96:160-164

33. Parsien JS, Shaffer B: Arthroscopic management of pyarthrosis. Clin Orthop 1992, 275:243-247.

34. Gainor BJ: Instillation of continuous tube irrigation in the septic knee at arthroscopy. Clin Orthop 1984, 183:96-98.

35. Ivey M, Clark R: Arthroscopic debridement of the knee for septic arthritis. Clin Orthop Rel Res 1985, 199:201-206

36. Bauer TW, Parvizi J, Kobayashi N, Krebs V: Diagnosis of periprosthetic infection. J Bone Joint Surg Am 2006, 88:869-882.

37. Gächter A: Joint infection - arthroscopic lavage - hints and tricks. Arthroskopie 1994, 7:98-102.

38. Frimodt-Moller N, Riegels-Nielsen P: Antibiotic penetration into the infected knee A rabbit experiment. Acta Orthop Scand 1987, 58:256-259.

39. Nelson JD: Antibiotic concentrations in septic joint effusion. N Engl J Med 1971, 284:349-353.

40. Patel H, Nade S: Acute staphylococcal septic arthritis: The effect of cloxacillin therapy in an avian model. J Orthop Res 1988, 6:63-72.

41. Lob G: The infected knee joint. In (Hrsg) Knee Hippokrates Stuttgart Edited by: Burri C, Mutschler W 1982, 46-51.

42. Gächter A: Joint infection. Inform Arzt 1985, 6:35-43.

43. Kuner EH, Thürck HU, von der Lippe I: Diagnosis and therapy of acute infections of the knee joint. Unfallchirurgie 1987, 13:249-254.

44. Gächter A: Arthroscopic lavage for joint infections. Orthopaed Traumatol 1993, 2:104-106.

45. Smith MJ: Arthroscopic treatment of the septic knee. Arthroscopy 1986, 2:30-34.

46. Ballabaud L, Gaudias J, Boeri C, Jenny J-Y, Kehr P: Results of treatment of septic knee arthritis: a retrospective series of 40 cases. Knee Surg Sports Traumatol Arthrosc 2007, 15:387-392.

47. Armstrong RW, Bolding F, Joseph R: Septic arthritis following arthroscopy: clinical syndromes and analysis of risk factors. Arthroscpoy 1992, 8:213-223

48. Jerosch J, Schröder M, Steinbeck J, Halm H: Arthroscopic therapy of bacterial arthritis. Arthroskopie 1994, 7:115-122.

49. Riel K-A, Primbs J, Bernett P: Arthroscopic distension irrigation in acute postoperative infection of the knee joint - long term follow up. Chirurg 1994, 65:1023-1027. 
50. Lamme B, Mahler CW, van Till JW, van Ruler O, Gouma DJ, Boermeester MA: Relaparotomy in secondary peritonitis: Planned relaparotomy or relaparotomy on demand? Chirurg 2005, 76:856-867.

\section{Pre-publication history}

The pre-publication history for this paper can be accessed here: http://www.biomedcentral.com/1471-2474/12/180/prepub

doi:10.1186/1471-2474-12-180

Cite this article as: Ateschrang et al:: Septic arthritis of the knee:

Presentation of a novel irrigation-suction system tested in a cadaver study. BMC Musculoskeletal Disorders 2011 12:180.

Submit your next manuscript to BioMed Central and take full advantage of:

- Convenient online submission

- Thorough peer review

- No space constraints or color figure charges

- Immediate publication on acceptance

- Inclusion in PubMed, CAS, Scopus and Google Scholar

- Research which is freely available for redistribution 